\title{
Current Status of \\ Castration-Resistant \\ Prostate Cancer Drug \\ Therapy
}

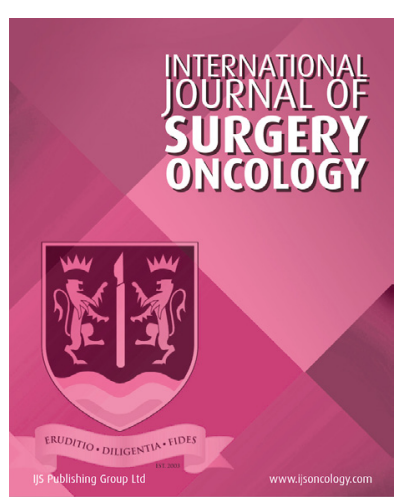

\author{
YIFENG MAO (D) \\ ERKE GAO \\ MINGQIU HU \\ WENBANG CHEN
}

GAOWEI YANG

*Author affiliations can be found in the back matter of this article

\section{ABSTRACT}

Objective: To explore the current therapies on castration-resistant prostate cancer (CRPC), such as drug therapy and radiotherapy.

Recent Advances: Currently, CRPC is an incurable disease. CRPC treatment options available can only relieve symptoms and prolong the survival time. Because of the in-depth study of resistance mechanisms, various new drugs have been reported, including androgen synthetic inhibitor, abiraterone. Novel targeted therapy and immunotherapy have been thoroughly investigated. The recent advances in wellstudied radiotherapy and chemotherapy against CRCP have also been reviewed. In this review, we have summarized new generation hormone drugs (e.g., abiraterone, enzalutamid), chemotherapeutic drugs (docetaxel), targeted therapy drugs, immunotherapy drugs (Sipulecel-T), and radioactive drugs (Radium 223). The overall treatment goals include to prolong OS, to improve quality of life, to relieve symptoms, and to prevent complications in CRCP patients.

Conclusions: The use of drug therapy in combination with other drugs might improve the efficacy of CRPC treatment and might help overcome drug resistance. 


\section{INTRODUCTION}

Prostate cancer is the second most common cancer and the fifth leading cause of male cancer deaths worldwide. According to GLOBOCAN statistics, a total of 1, 276, 106 new cases and 358, 989 deaths occurred in 2018 worldwide [1]. Prostate cancer is the second most common male malignant tumor in the United States [2]. The American Cancer Society estimated 250, 000 new cases and 34, 000 deaths in the United States in 2021 [3]. A statistical study reported about 72, 000 new cases of prostate cancer and 30, 700 deaths in China in 2015 prostate cancer ranked sixth in the incidence spectrum and tenth in the death spectrum of male malignant tumors [4]. In contrast, the incidence and mortality rate in China are slightly lower than the global level; however, an increased tendency has been observed in China in recent years.

In 1941, Huggins et al. reported that castration treatment or a large dose of estrogen injection could cause a sharp decrease in acid phosphatase level or decrease it to the normal level [5]. Since then, androgen deprivation therapy (ADT) has been a common therapy for locally advanced or metastatic prostate cancer. However, most patients with metastatic hormonesensitive prostate cancer developed castration-resistant prostate cancer (CRPC) within 2-3 years after the beginning of ADT treatment, and the patients had low circulating testosterone level $[6,7]$, The median survival of patients with CRPC was 15-36 months; however, the specific survival rate depended on the disease's severity [8]. European Urology Association defines CRPC as castrated serum testosterone $<50 \mathrm{ng} / \mathrm{dL}$ or $1.7 \mathrm{nmol} / \mathrm{L}$ with biochemical progression (prostate-specific antigen (PSA) successively rises three times in a week, two of which exceed $50 \%$ of the lowest point, PSA $>2 \mathrm{ng} / \mathrm{mL}$ ) or radiological progression (bone scans show two or more new bone lesions or Response Evaluation Criteria in Solid Tumors is applied to show soft tissue lesions) [9].

Although CRPC cannot be cured, various drugs can delay disease development and the overall survival (OS) of patients can be prolonged. In this review, we have summarized new generation hormone drugs (e.g., abiraterone, enzalutamid), chemotherapeutic drugs (docetaxel), targeted therapy drugs, immunotherapy drugs (Sipulecel-T), and radioactive drugs (Radium 223) (Table 1).

\section{NOVEL HORMONE DRUG THERAPY 2.1 ANDROGEN SYNTHETIC INHIBITOR}

Abiraterone is an effective inhibitor of cytochrome P450-C17, which is an essential enzyme in androgen synthesis mediated by cholesterol. It can effectively block androgen synthesis in the adrenal gland, testis, and prostate tumors by inhibiting hydroxylase and lyase activities irreversibly $[10,11]$. In phase III trials, a total of
1, 199 patients with CRPC were randomly divided into the abiraterone group (ADT + abiraterone + prednison) and the placebo group (ADT + double placebo). The results showed that the median survival time of patients in the abiraterone group was significantly longer than that of patients in the placebo group (hazard ratio of death: 0.62; 95\%CI: 0.51 0.76; P<0.001). The median survival time of radiographic progression-free of patients in the abiraterone group was significantly longer (33.0 months) than that of patients in the placebo group (hazard ratio of disease progression or death: 0.47; 95\% CI: 0.39 0.55; P< 0.001 ). Abiraterone acetate and prednisone significantly increased the overall survival rate and radiographic progression-free survival rate in patients with newly diagnosed, metastatic, castration sensitive prostate cancer [12].

In the SWITCH study, 26 metastatic CRPC (mCRPC) patients with PSA and/or limited radiological progression received abiraterone + dexamethasone (AAD) treatment for at least 12 weeks after AAP treatment. The results showed that PSA30 and PSA50 were $46.2 \%$ and $34.6 \%$, respectively. The median time of biochemical and radiological progression was 5.3 and 11.8 months, respectively. The average OS was 20.9 months. These results indicated that steroid conversion was a feasible and safe strategy in the case of abiraterone resistance after its long-term use [13].

\subsection{ANDROGEN RECEPTOR (AR) INHIBITOR}

\subsubsection{Enzalutamid}

As a second-generation androgen receptor (AR) inhibitor, enzalutamid can directly bind to the AR to block androgen synthesis, AR nuclear translocation, and DNA binding mediated by androgen. Enzalutamid can be used in the treatment of non-metastatic and metastatic diseases including mCRPC at the beginning of chemotherapy [14, 15]. In a latest study, patients with non-metastatic CRPC (nmCRPC) were randomly divided into the enzalutamid group and the placebo group at a ratio of 2:1. The median OS in the enzalutamid group was 67.0 months (hazard ratio of death: $0.73 ; 95 \% \mathrm{CI}$ : 0.61 0.89; $\mathrm{P}=0.001)$. The results indicated that PSA level in patients with nmCRPC increased rapidly, indicating that enzalutamid could prolong the median OS and lower the death risk. [16]

No significant difference was found among PSA progression, clinical or radiological progression, or disease death in a comparative experiment with abiraterone. However, enzalutamid showed a better PSA response and the proportion of patients with PSA reduction $\geq 50 \%$ within 12 weeks was higher than that of abiraterone ( $75 \%$ vs. $54 \%, P=0.004$, Fisher exact test) [17]. In another study combined with AAP, patients in the combined and control groups had similar progressionfree survival time. However, grade 3 hypertension (10\% vs. $2 \%$ ) and high alanine aminotransferase (6\% vs. $2 \%$ ) or aspartate aminotransferase(AST) (2\% vs. 0\%) were more 


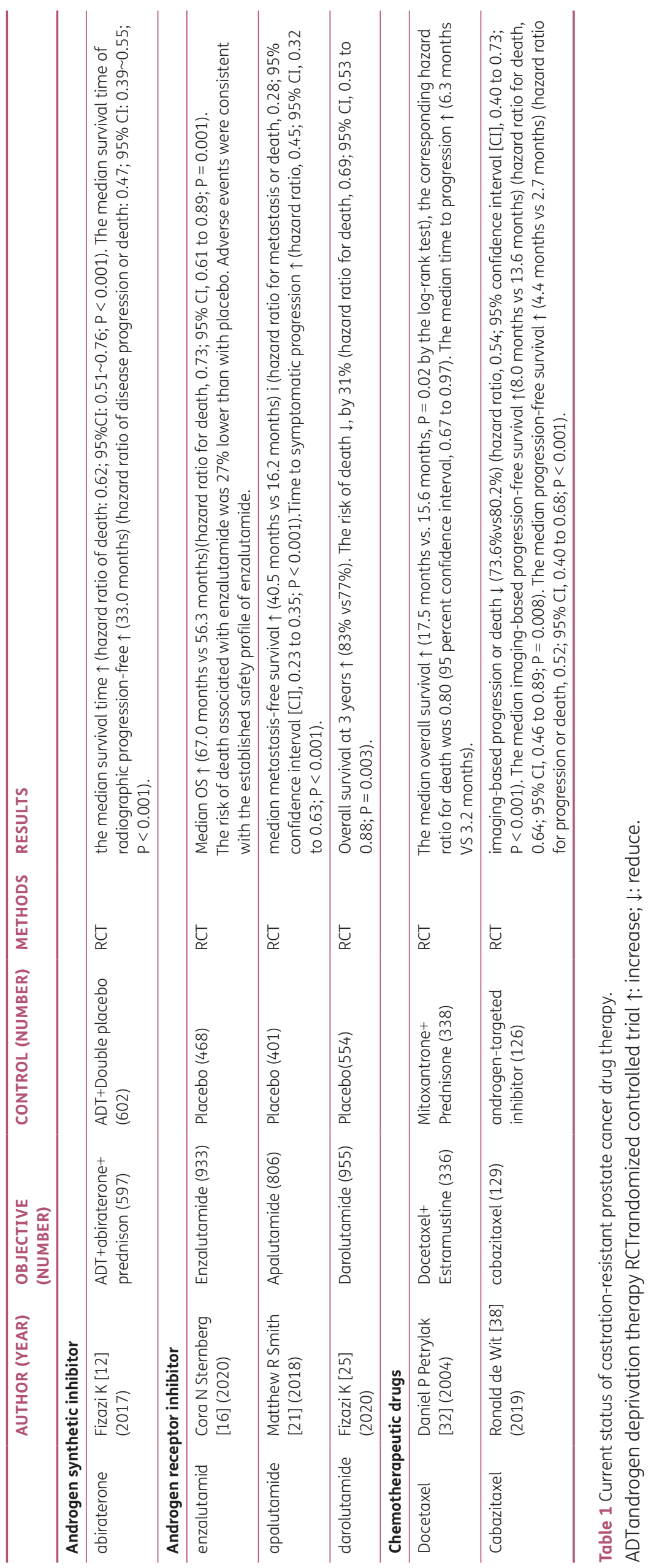


frequent in the combined group than those in the control group. These results indicated that during enzalutamid treatment, a higher rate of side effects was observed when it was combined with enzalutamid, abiraterone, and prednisone [18].

\subsubsection{Apalutamide}

Apalutamide is a high-affinity AR inhibitor and can prevent AR nuclear translocation [19, 20]. In phase III trial, a total of 1, 201 patients with nmCRPC were randomly divided into the apalutamide group and placebo group at a ratio of 2:1. The results demonstrated that the median metastasis-free survival time in the apalutamide group extended by 24.3 months (hazard ratio of metastasis or death: 0.28; 95\%CI: 0.23 0.35; P < 0.001) and the time to symptomatic progression was significantly longer than that in the placebo group (hazard ratio: 0.45; 95\%CI: 0.32 0.63; P<0.001). The results demonstrated that apalutamide had a significant clinical response in patients with nmCRPC [21].

A total of 1171 SPARTAN patients were matched with 1, 401 PROSPER patients. Based on the matchingadjusted indirect comparison method, we found that the incidence of fatigue $[p(O R<1)=99.5 \%]$, hypertension [p $(\mathrm{OR}<1)=99.2 \%]$, headache $[\mathrm{p}(\mathrm{OR}<1)=86.7 \%]$, nausea $[\mathrm{P}(\mathrm{or}<1)=80.0 \%$ ], and loss of appetite [p (OR $<1)=98.3 \%$ in the apalutamide group was significantly lower than that in the enzalutamid group. Apalutamide treatment decreased the incidence of adverse events and serious adverse events by $66.9 \%$ and $90.9 \%$, respectively, patients administered with apalutamide had a higher tolerance toward nmCRCP treatment [22]. However, patients who received apalutamide were more likely to develop multiple sclerosis and osteoarthritis than those who received enzalutamid [23].

\subsubsection{Darolutamide}

Darolutamide is an androgen inhibitor with a unique structure, and has been approved for nmCRPC treatment [24]. In the latest research, a total of 1, 509 males were randomly divided into the darolutamide group (955 patients) and placebo group (554 patients). The results showed that the 3 -year survival rate was $83 \%$ in the darolutamide group (95\%CI: $80 \sim 86$ ) and $77 \%$ in the placebo group (95\%CI: 72 81). The risk of death reduced to $31 \%$ (hazard ratio of death: 0.69 ; $95 \% \mathrm{CI}$ : $0.53 \sim 0.88$; $\mathrm{P}=0.003$ ). These results indicated that the metastasisfree survival time and OS of patients with nmCRPC were significantly prolonged after darolutamide treatment without changing the rate of adverse reactions [25].

Darolutamide can inhibit the growth of enzalutamidresistant MR49F cells and $A R$ transcription activity in vitro. Moreover, darolutamide also significantly inhibited the transcriptional activity of the mutant, which could convert enzalutamid into a partial agonist, such as F877L, H875Y/T878A, and F877L/T878A. Darolutamide can be used to delay the growth of enzalutamid-resistant prostate cancer [26].

The direct comparative data on nmCRPC treatment with new generation AR inhibitor is lacking, and is present only in the form of network meta-analysis. Apalutamide has been the best choice for metastasisfree survival(MFS) ( $P=0.8809$ ). Apalutamide has been the leading scheme for PSA-benign prostatic hyperplasia syndrome $(P=1.000)$. Darolutamide has been the best choice for adverse events (e.g., grade 3 or 4 adverse events, grade 5 adverse events, and drug withdrawal rate). Apalutamide and enzalutamid are effective drugs for nmCRPC treatment, whereas darolutamide has the most favorable tolerance [27].

\section{CHEMOTHERAPEUTIC DRUGS}

Mitoxantrone was approved by the Food and Drug Administration (FDA) for mCRPC treatment in 1996. In two clinical trials (in 1996 and 2002), mitoxantrone did not affect the survival rate of patients [28, 29]. SUN 1120 and TERIC data analysis showed that the median survival time of patients treated with mitoxantrone + prednisone was similar to that of patients treated with prednison only (385 days vs. 336 days; deceleration factor $=0.04 ; 95 \%$ CI: -0.12 to 0.22 ). Research showed that mitoxantrone had no considerable survival benefit after docetaxel treatment [30], and was gradually replaced by docetaxel and cabazitaxel.

Docetaxel can induce apoptosis by inhibiting microtubule depolymerization and by blocking antiapoptotic signal, and can be used as the first-line drug for mCRPC treatment. The TAX327 test and the Southwest Oncology Group (SWOG) 99-16 test confirmed that docetaxel could improve the median OS of mCRPC patients (1.9-2.4 months) [31-33].

A total of 98 CRPC patients, including $46 \mathrm{nmCRPC}$ patients and $52 \mathrm{nmCRPC}$ patients who received docetaxel treatment were analyzed in a trial. OS of patients in the nmCRPC group was significantly longer than that of patients in the MCRPC group (not reached vs. 52.2 months, $P=0.006$ ). For patients with $n m C R P C$, the early induction of docetaxel might have prolonged OS [34].

Cabazitaxel leads to cell death via tubulin stabilization, and can be used to overcome docetaxel resistance mediated by multidrug resistance protein (P-glycoprotein). Cabazitaxel has been approved to treat $\mathrm{MCRPC}$ patients that were previously treated with docetaxel but developed docetaxel resistance [35-37]. A total of 255 mCRPC patients who had previously received docetaxel and androgen-targeted inhibitor were randomly divided into the cabazitaxel group (129 patients) and androgen-targeted inhibitor group (126 patients) at a ratio of 1:1. In the cabazitaxel group, the median of progression-free survival time based on the 
radiography extended by 4.3 months, the median OS prolonged by 2.6 months (hazard ratio of death: 0.64 ; 95\%CI: 0.46 to $0.89 ; P=0.008$ ), and the median of progression-free survival time extended by 1.7 months (hazard ratio of progression or death: 0.52; 95\% CI: 0.40 to $0.68 ; \mathrm{P}<0.001)$. Studies have shown that cabazitaxel considerably improved the clinical outcomes in patients with $\mathrm{MCRPC}$ who had previously received docetaxel or AR-targeted inhibitor [38].

\section{TARGETED DRUGS}

Poly(adenosine diphosphate-ribose) polymerase (PARP) is a ribozyme that plays an essential role in cell repair mediated by deoxynucleotide. Tumor cells with BRCA1/2 or Ataxia telangiectasia mutated (ATM) deficiency require DNA repair mediated by PAPR. Studies have shown that about $20 \%$ of patients with $\mathrm{mCRPC}$ had significant mutations in BRCA1/2 or ATM [39-41].

Olaparib is a PARP inhibitor and has been approved by the FDA for the treatment of BRCA1/2 or ATM mutant CRPC in January 2016 with approximately $90 \%$ of effective rate [42]. In phase III trial, $245 \mathrm{mCRPC}$ patients with new hormone drug resistance who had at least one change in BRCA1, BRCA2, and ATM were divided into the olaparib group and the control group at a ratio of 2:1. The results showed that radiographic progression-free survival time in the olaparib group was significantly extended $(7.4 \mathrm{~m}$ vs. $3.6 \mathrm{~m}$; hazard ratio of progression or death: $0.34 ; 95 \%$ CI: 0.25 to $0.47 ; p<0.001$ ) and anemia and nausea were the main toxic reactions [43].

Treatment of $\mathrm{mCRPC}$ by another PARP inhibitor, rucaparib, requires further study [44]. In TRITON2 trial, 115 mCRPC patients (BRCA1/BRCA2 change) administered with $A R$ inhibitors and chemotherapeutic drugs were treated with $600 \mathrm{mg}$ rucaparib twice a day.

The results showed that the risk rate of radiology examination was $43.5 \%$ (95\%CI: $31.0 \%$ to $56.7 \%$; 27 out of 62 patients), the response rate of PSA was $54.8 \%$ (95\%CI: $45.2 \%$ to $64.1 \%$; 63 out of 115 patients) and the most common treatment-emergent adverse event $\geq$ grade 3 was anemia (25.2\%; 29 out of 115 patients). Rucaparib treatment showed changes in anti-tumor activity against breast cancer in MCRPC patients; however, breast cancer has the same manageable safety as other solid tumor types [45].

\section{IMMUNOTHERAPY}

Sipulecel-T is the only immunotherapeutic drug approved by the FDA, and is used to treat asymptomatic or minimum symptomatic mCRPC. The activation of antigen-presenting cells can induce strong and longlasting antigen-specific humoral and $T$ cell reactions and $T$ cells transport to tumor tissue, which stimulates local and systemic cytotoxic T lymphocyte activity and promotes antigen diffusion. Based on IMPACT trial, the median OS of patients was prolonged by 3.4 months [46, 47].

A total of 3216 patients administered with sipuleucel-T from 2010 to 2017 had the most common adverse reactions including shivering $(n=318)$, discomfort $(n=$ $196)$, fever ( $n=189)$, fatigue $(n=180)$, and nausea ( $n$ = 173) [48]. In one trial, 18 patients with mCRPC were divided into two groups; one group received intradermal injection with Sipuleucel-T and another received PTVGHP DNA vaccine alone. A high titer of PAP antibody was detected in patients receiving supplementary PTVGHP vaccine. These results indicated that the initial supplementary vaccination could enhance and diversify the immune responses induced by anti-tumor vaccine. Further studies on DNA vaccines as an immune promoter need to be performed. [49]

Programmed cell death protein-1 and its ligands, programmed death-ligand (PD-L) 1 and PD-L2, transmit signals that inhibit $T$ cell activation [50, 51]. Pembrolizumab has anti-tumor activity against positive mCRPC. KENNNETH-199 research showed that patients with bone-based MCRPC had acceptable safety with the disease control rate of $22 \%$ and the median OS of 14.1 months [52]. PD-L1 is associated with poor prognosis and advanced clinicopathological factors of prostate cancer. The analysis of 3, 133 patients before March 23, 2020 showed that PD-L1 protein expression and PD-L1 DNA methylation were negatively correlated with the biochemical recurrence-free survival rate, and their hazard ratios (HRs) were 1.67 (95\%CI $=1.38$ to $2.06, \mathrm{P}<0.001$ ) and $2.23(95 \% \mathrm{CI}=1.51$ to $3.29, \mathrm{P}<0.001)$, respectively. PD-L1 overexpression was significantly correlated with advanced prostate cancer $(\mathrm{OR}=1.40,95 \% \mathrm{CI}=1.13$ to 1.75, $\mathrm{p}=0.003)$ and positive $\mathrm{AR}(\mathrm{OR}=2.20,95 \% \mathrm{CI}=$ 1.61 to $3.01, P<0.001)$. PD-L1 was associated with poor prognosis and advanced clinicopathological factors of prostate cancer [53].

\section{RADIOACTIVE DRUGS 6.1 RADIUM 223}

Radium 223 is an -particle emitter and calcium mimic, which targets the hydroxyapatite matrix in the bone. Radium 223 accumulates in the areas of active bone remodeling and formation, such as the site of osteoblast bone metastasis. Radium 223 was administered to CRPC patients with bone metastasis symptoms without visceral metastasis, and it improved OS rate. [54, 55] In phase III trial, Radium 223 was administered to 708 patients with $\mathrm{mCRPC}$, among which 548 had various symptoms and 135 had no symptoms. The results showed that the OS (hazard ratio [HR] 0.486), the time of disease progression (HR 0.722), the time of the first bone event 
with a symptom (HR 0.328) in asymptomatic patients were better than those in symptomatic patients, and the PSA response rate was also higher in the asymptomatic patients (21\% vs. $13 \%)$. These results indicated that radium 223 could be considered a complete treatment option for asymptomatic CRPC patients or patients with mild symptoms [56]. In a latest trial, the supplementation of radium 223 in the AAP regimen did not improve the survival rate of CRPC patients with bone metastases, and the frequency of fracture increased. Therefore, radium 223 in combination with AAP is not recommended $[57,58]$.

\subsection{RADIOTHERAPY}

Prostate-specific membrane antigen (PSMA) is expressed on the cell membrane of prostate epithelial cells and is considerably upregulated in prostate cancer. PSMA is an appropriate target for diagnosing, treating, and determining the metastasis of prostate cancer $[59,60]$

177Lu-PSMA-617 is a potential new radioligand therapy for $\mathrm{MCRPC}$, and capable of targeted delivery of -particle radiation to prostate cancer [61-63]. The results showed that about $2 / 3$ of PSA and $1 / 3$ of PSA was decreased by more than $50 \%$, and the survival period was prolonged after the first week of radiotherapy [64]. In phase II prospective trial, 50 patients (short median time of PSA multiplication and extensive previous treatment) received 177 Lu-PSMA-617 with an average radiation dose of $7.5 \mathrm{GBq} /$ period for 4 cycles. A total of 22 patients (44\%; $95 \%$ CI: $30 \%$ to $59 \%$ ) had at least $50 \%$ of specific antigen reduction and 22 patients (44\%; 95\%CI: $30 \%$ to $59 \%$ ) had $80 \%$ of specific antigen reduction. With a median follow-up time of 31.4 months, median OS was 13.3 months (95\%CI: 10.5 to 18.7 months) and the survival time of patients with PSA decreased by at least $50 \%$ was significantly prolonged to 18.4 months (95\%CI: 13.8 to 23.8 months). The main adverse reactions were mouth dryness (66\%), transient nausea (48\%), thrombocytopenia (10\%), and anemia (10\%). These results indicated that 177Lu-PSMA-617 had a high response rate and low toxicity, and improved life quality [65].

\section{OUTLOOK}

CRPC is still an incurable disease. Currently, the main treatment goals are to prolong OS, improve quality of life, relieve symptoms, and prevent complications. Various drugs and their combinations have been reviewed to identify whether they can improve the curative effect and prevent drug resistance. The opening of new generation androgen drugs has dramatically improved the OS of CRPC patients; however, more research is needed on immunological drugs.

\section{FUNDING INFORMATION}

The present study was funded by the Key Projects of Provincial Educational Department, Anhui Province, China Mainland (grant no. KJ2019A0373), and Bengbu Medical College, Anhui Province, China mainland (grant no. BYKC201912).

\section{COMPETING INTERESTS}

The authors have no competing interests to declare.

\section{AUTHOR CONTRIBUTIONS}

Yifeng Mao contributions: data collection, drafting and critical revision of the manuscript. Mingqiu Hu contributions: drafting and critical revision of the manuscript.

Gaowei Yang, Erke Gao and Wenbang Chen contributions: study design and conception, drafting and critical revision of the manuscript. All authors read and approved the final manuscript.

\section{AUTHOR AFFILIATIONS}

Yifeng Mao (D) orcid.org/0000-0001-6016-1883 Bengbu Medical College, Anhui 233030, China; Department of Urology, The Second Affiliated Hospital of Bengbu Medical College, Anhui 233030, China; Anhui Province Key Laboratory of Translational Cancer Research, Bengbu Medical University, Anhui 233030, China

\section{Mingqiu Hu}

Bengbu Medical College, Anhui 233030, China; Department of Urology, The Second Affiliated Hospital of Bengbu Medical College, Anhui 233030, China; Anhui Province Key Laboratory of Translational Cancer Research, Bengbu Medical University, Anhui 233030, China; Department of Urology, Maoming People's Hospital, Guangdong 525000, China

\section{Gaowei Yang}

Bengbu Medical College, Anhui 233030, China

\section{Erke Gao}

Bengbu Medical College, Anhui 233030, China

Wenbang Chen

Bengbu Medical College, Anhui 233030, China

\section{REFERENCES}

1. Bray F, Ferlay J, Soerjomataram I, Siegel RL, Torre LA, et al. Global cancer statistics 2018: GLOBOCAN estimates of incidence and mortality worldwide for 36 cancers in 185 countries. CA Cancer J Clin. 2018; 68: 394-424. DOI: https:// doi.org/10.3322/caac.21492

2. Henley SJ, Ward EM, Scott S, Ma J, Anderson RN, et al. Annual report to the nation on the status of cancer, part I: National cancer statistics. Cancer. 2020; 126: 2225-49. DOI: https://doi.org/10.1002/cncr.32802 
3. Siegel RL, Miller KD, Fuchs HE, Jemal A. Cancer Statistics, 2021. CA Cancer J Clin. 2021; 71: 7-33. DOI: https://doi. org/10.3322/caac.21654

4. Fu Z, Guo X, Zhang S, Zheng R, Zeng $\mathbf{H}$, et al. Statistical analysis of incidence and mortality of prostate cancer in China, 2015. Chinese Journal of Oncology. 2020; 42: 718-72.

5. Huggins $\mathbf{C}$, Hodges CV. Studies on prostatic cancer: I. The effect of castration, of estrogen and of androgen injection on serum phosphatases in metastatic carcinoma of the prostate 1941. J Urol. 2002; 168: 9-12. DOI: https://doi. org/10.1016/S0022-5347(05)64820-3

6. Damodaran S, Lang JM, Jarrard DF. Targeting Metastatic Hormone Sensitive Prostate Cancer: Chemohormonal Therapy and New Combinatorial Approaches. J Urol. 2019; 201: 876-85. DOI: https://doi.org/10.1097/ JU.0000000000000117

7. Goetz D. New options for the management of CRPC: a case perspective. J Natl Compr Canc Netw. 2011; 9: S13-23; S24. DOI: https://doi.org/10.6004/jnccn.2011.0128

8. Dong L, Zieren RC, Xue W, de Reijke TM, Pienta KJ. Metastatic prostate cancer remains incurable, why? Asian J Urol. 2019; 6: 26-41. DOI: https://doi.org/10.1016/j. ajur.2018.11.005

9. Heidenreich A, Bastian PJ, Bellmunt J, Bolla M, Joniau S, et al. EAU guidelines on prostate cancer. Part II: Treatment of advanced, relapsing, and CRPC. Eur Urol. 2014; 65: 46779. DOI: https://doi.org/10.1016/j.eururo.2013.11.002

10. Mostaghel EA. Abiraterone in the treatment of metastatic CRPC. Cancer Manag Res. 2014; 6: 39-51. DOI: https://doi. org/10.2147/CMAR.S39318

11. Li A, Turro C, Kodanko JJ. Ru (ii) polypyridyl complexes as photocages for bioactive compounds containing nitriles and aromatic heterocycles. Chem Commun (Camb). 2018; 54: 1280-90. DOI: https://doi.org/10.1039/C7CCO9000E

12. Fizazi K, Tran N, Fein L, Matsubara N, Rodriguez-Antolin A, et al. Abiraterone plus Prednisone in Metastatic, Castration-Sensitive Prostate Cancer. N Engl J Med. 2017; 377: 352-60. DOI: https://doi.org/10.1056/NEJMoa1704174

13. Romero-Laorden N, Lozano R, Jayaram A, López-Campos F, Saez MI, et al. Phase II pilot study of the prednisone to dexamethasone switch in metastatic CRPC (mCRPC) patients with limited progression on abiraterone plus prednisone (SWITCH study). Br J Cancer. 2018; 119: 1052-9. DOI: https://doi.org/10.1038/s41416-018-0123-9

14. Scott LJ. Enzalutamide: A Review in CRPC. Drugs. 2018; 78: 1913-24. DOI: https://doi.org/10.1007/s40265-018-1029-9

15. Kregel S, Chen JL, Tom W, Krishnan V, Kach J, et al. Acquired resistance to the second-generation androgen receptor antagonist enzalutamide in CRPC. Onco Target. 2016; 7: 26259-74. DOI: https://doi.org/10.18632/ oncotarget. 8456

16. Sternberg CN, Fizazi K, Saad F, Shore ND, De Giorgi U, et al. Enzalutamide and Survival in Nonmetastatic, CRPC. N Engl J Med. 2020; 382: 2197-206. DOI: https://doi. org/10.1056/NEJMoa2003892
17. Annala M, Vandekerkhove G, Khalaf D, Taavitsainen S, Beja K, et al. Circulating Tumor DNA Genomics Correlate with Resistance to Abiraterone and Enzalutamide in Prostate Cancer. Cancer Discov. 2018; 8: 444-57. DOI: https://doi.org/10.1158/2159-8290.CD-17-0937

18. Attard G, Borre M, Gurney H, Loriot Y, AndresenDaniil C, et al. Abiraterone Alone or in Combination with Enzalutamide in Metastatic CRPC with Rising ProstateSpecific Antigen During Enzalutamide Treatment. J Clin Oncol. 2018; 36: 2639-46. DOI: https://doi.org/10.1200/ JCO.2018.77.9827

19. Borno HT, Small EJ. Apalutamide and its use in the treatment of prostate cancer. Future Oncol. 2019; 15: 591 599. DOI: https://doi.org/10.2217/fon-2018-0546

20. Rathkopf DE, Scher HI. Apalutamide for the treatment of prostate cancer. Expert Rev Anticancer Ther. 2018; 18: 823 836. DOI: https://doi.org/10.1080/14737140.2018.1503954

21. Smith MR, Saad F, Chowdhury S, Oudard S, Hadaschik BA, et al. Apalutamide Treatment and Metastasis-free Survival in Prostate Cancer. N Engl J Med. 2018; 378: 1408-18. DOI: https://doi.org/10.1056/NEJMoa1715546

22. Chowdhury S, Oudard S, Uemura H, Joniau S, Pilon D, et al. Matching-Adjusted Indirect Comparison of Health-Related Quality of Life and Adverse Events of Apalutamide Versus Enzalutamide in Non-Metastatic CRPC. Adv Ther. 2020; 37 : 512-26. DOI: https://doi.org/10.1007/s12325-019-01157-4

23. Chowdhury S, Oudard S, Uemura H, Joniau S, Pilon D, et al. Matching-Adjusted Indirect Comparison of the Efficacy of Apalutamide and Enzalutamide with ADT in the Treatment of Non-Metastatic CRPC. Adv Ther. 2020; 37: 501-11. DOI: https://doi.org/10.1007/s12325-019-01156-5

24. Markham A, Duggan S. Darolutamide: First Approval. Drugs. 2019; 79: 1813-18. DOI: https://doi.org/10.1007/s40265019-01212-y

25. Fizazi K, Shore N, Tammela TL, Ulys A, Vjaters E, et al. Nonmetastatic, CRPC and Survival with Darolutamide. N Engl J Med. 2020; 383: 1040-9. DOI: https://doi. org/10.1056/NEJMoa2001342

26. Borgmann H, Lallous N, Ozistanbullu D, Beraldi E, Paul $\mathbf{N}$, et al. Moving Towards Precision Urologic Oncology: Targeting Enzalutamide-resistant Prostate Cancer and Mutated Forms of the Androgen Receptor Using the Novel Inhibitor Darolutamide (ODM-201). Eur Urol. 2018; 73: 4-8. DOI: https://doi.org/10.1016/j.eururo.2017.08.012

27. Mori K, Mostafaei H, Pradere B, Motlagh RS, Quhal F, et al. Apalutamide, enzalutamide, and darolutamide for non-metastatic CRPC: a systematic review and network meta-analysis. Int J Clin Oncol. 2020; 25: 1892-900. DOI: https://doi.org/10.1007/s10147-020-01777-9

28. Kantoff PW, Halabi S, Conaway M, Picus J, Kirshner J, et al. Hydrocortisone with or without mitoxantrone in men with hormone-refractory prostate cancer: results of the cancer and leukemia group B 9182 study. J Clin Oncol. 1999; 17: 2506-13. DOI: https://doi.org/10.1200/ JCO.1999.17.8.2506 
29. Berry W, Dakhil S, Modiano M, Gregurich M, Asmar L. Phase III study of mitoxantrone plus low dose prednisone versus low dose prednisone alone in patients with asymptomatic hormone refractory prostate cancer. J Urol. 2002; 168: 2439-43. DOI: https://doi.org/10.1016/S00225347(05)64163-8

30. Green AK, Corty RW, Wood WA, Meeneghan M, ReederHayes KE, et al. Comparative effectiveness of mitoxantrone plus prednisone versus prednisone alone in metastatic castrate-resistant prostate cancer after docetaxel failure. Oncologist. 2015; 20: 516-22. DOI: https://doi.org/10.1634/ theoncologist.2014-0432

31. Teo MY, Rathkopf DE, Kantoff P. Treatment of Advanced Prostate Cancer. Annu Rev Med. 2019; 70: 479-99. DOI: https://doi.org/10.1146/annurev-med-051517-011947

32. Petrylak DP, Tangen CM, Hussain MH, Lara PN, Jr, Jones JA, et al. Docetaxel and estramustine compared with mitoxantrone and prednisone for advanced refractory prostate cancer. N Engl J Med. 2004; 351: 1513-20. DOI: https://doi.org/10.1056/NEJMoa041318

33. Tannock IF, de Wit R, Berry WR, Horti J, Pluzanska A, et al. Docetaxel plus prednisone or mitoxantrone plus prednisone for advanced prostate cancer. N Engl J Med. 2004; 351: 1502-12. DOI: https://doi.org/10.1056/NEJMoa040720

34. Ito K, Kimura T, Onuma H, Tabata R, Shimomura T, et al. Does docetaxel prolong survival of patients with nonmetastatic CRPC? Prostate. 2018; 78: 498-505. DOI: https:// doi.org/10.1002/pros.23493

35. Al-Mansouri L, Gurney H. Clinical concepts for cabazitaxel in the management of metastatic CRPC. Asia Pac J Clin Oncol. 2019; 15: 288-95. DOI: https://doi.org/10.1111/ ajco.13193

36. de Bono JS, Oudard S, Ozguroglu M, Hansen S, Machiels JP, et al. Prednisone plus cabazitaxel or mitoxantrone for metastatic CRPC progressing after docetaxel treatment: a randomised open-label trial. Lancet. 2010; 376: 1147-54. DOI: https://doi.org/10.1016/S0140-6736(10)61389-X

37. de Wit R, de Bono J, Sternberg CN, Fizazi K, Tombal B, et al. Cabazitaxel versus Abiraterone or Enzalutamide in Metastatic Prostate Cancer. N Engl J Med. 2019; 381: 250618. DOI: https://doi.org/10.1056/NEJMoa1911206

38. de Wit R, de Bono J, Sternberg CN, Fizazi K, Tombal B, et al. Cabazitaxel versus Abiraterone or Enzalutamide in Metastatic Prostate Cancer. N Engl J Med. 2019; 381: 2506 18. DOI: https://doi.org/10.1056/NEJMoa1911206

39. Brönimann S, Lemberger U, Bruchbacher A, Shariat SF, Hassler MR. Poly (ADP-ribose) polymerase inhibitors in prostate and urothelial cancer. Curr Opin Urol. 2020; 30: 519-26. DOI: https://doi.org/10.1097/ MOU.0000000000000776

40. Ma Y, He L, Huang Q, Zheng S, Zhang Z, et al. Response to olaparib in metastatic CRPC with germline BRCA2 mutation: a case report. BMC Med Genet. 2018; 19: 185. DOI: https:// doi.org/10.1186/s12881-018-0703-9

41. Robinson D, Van Allen EM, Wu YM, Schultz N, Lonigro RJ, et al. Integrative clinical genomics of advanced prostate cancer. Cell. 2015; 161: 1215-28. DOI: https://doi. org/10.1016/j.cell.2015.05.001

42. Martin GA, Chen AH, Parikh K. A Novel Use of Olaparib for the Treatment of Metastatic Castration-Recurrent Prostate Cancer. Pharmacotherapy. 2017; 37: 1406-14. DOI: https:// doi.org/10.1002/phar.2027

43. de Bono J, Mateo J, Fizazi K, Saad F, Shore N, et al. Olaparib for Metastatic CRPC. N Engl J Med. 2020; 382: 2091-102. DOI: https://doi.org/10.1056/NEJMoa1911440

44. Rescigno P, Chandler R, de Bono J. Relevance of poly (ADPribose) polymerase inhibitors in prostate cancer. Curr Opin Support Palliat Care. 2018; 12: 339-43. DOI: https://doi. org/10.1097/SPC.0000000000000358

45. Abida W, Patnaik A, Campbell D, Shapiro J, Bryce AH, et al. Rucaparib in Men with Metastatic CRPC Harboring a BRCA1 or BRCA2 Gene Alteration. J Clin Oncol. 2020; 38: 3763-72. DOI: https://doi.org/10.1200/JCO.20.01035

46. Reimers MA, Slane KE, Pachynski RK. Immunotherapy in Metastatic CRPC: Past and Future Strategies for Optimization. Curr Urol Rep. 2019; 20: 64. DOI: https://doi. org/10.1007/s11934-019-0931-3

47. Madan RA, Antonarakis ES, Drake CG, Fong L, Yu EY, et al. Putting the Pieces Together: Completing the Mechanism of Action Jigsaw for Sipuleucel-T. J Natl Cancer Inst. 2020; 112: 562-73. DOI: https://doi.org/10.1093/jnci/djaa021

48. Dores GM, Bryant-Genevier M, Perez-Vilar S. Adverse Events Associated with the Use of Sipuleucel-T Reported to the US Food and Drug Administration's Adverse Event Reporting System, 2010-2017. JAMA Netw Open. 2019; 2: e199249. DOI: https://doi.org/10.1001/ jamanetworkopen.2019.9249

49. Wargowski E, Johnson LE, Eickhoff JC, Delmastro L, Staab MJ, et al. Prime-boost vaccination targeting prostatic acid phosphatase (PAP) in patients with metastatic CRPC (mCRPC) using Sipuleucel-T and a DNA vaccine. J Immunother Cancer. 2018; 6: 21. DOI: https://doi. org/10.1186/s40425-018-0333-y

50. Bansal D, Reimers MA, Knoche EM, Pachynski RK. Immunotherapy and Immunotherapy Combinations in Metastatic CRPC. Cancers (Basel). 2021; 13: 334. DOI: https://doi.org/10.3390/cancers13020334

51. Handa S, Hans B, Goel S, Bashorun HO, Dovey Z, et al. Immunotherapy in prostate cancer: current state and future perspectives. Ther Adv Urol. 2020; 12: 1756287220951404. DOI: https://doi. org/10.1177/1756287220951404

52. Antonarakis ES, Piulats JM, Gross-Goupil M, Goh J, Ojamaa K, et al. Pembrolizumab for Treatment-Refractory Metastatic CRPC: Multicohort, Open-Label Phase II KEYNOTE-199 Study. J Clin Oncol. 2020; 38: 395-405. DOI: https://doi.org/10.1200/JC0.19.01638

53. Shen H, Liu J, Sun G, Yan L, Li Q, et al. The clinicopathological significance and prognostic value of programmed death-ligand 1 in prostate cancer: a metaanalysis of 3133 patients. Aging (Albany NY). 2020; 13 2279-93. DOI: https://doi.org/10.18632/aging.202248 
54. Gallicchio R, Mastrangelo PA, Nardelli A, Mainenti PP, Colasurdo AP, et al. Radium-223 for the treatment of bone metastases in CRPC: when and why. Tumori. 2019; 105: 367-77. DOI: https://doi.org/10.1177/0300891619851376

55. Poeppel TD, Handkiewicz-Junak D, Andreeff M, Becherer A, Bockisch A, et al. EANM guideline for radionuclide therapy with radium-223 of metastatic CRPC. Eur J NuCl Med Mol Imaging. 2018; 45: 824-45. DOI: https://doi. org/10.1007/s00259-017-3900-4

56. Heidenreich A, Gillessen S, Heinrich D, Keizman D, O'Sullivan JM, et al. Radium-223 in asymptomatic patients with CRPC and bone metastases treated in an international early access program. BMC Cancer. 2019; 19: 12. DOI: https://doi.org/10.1186/s12885-018-5203-y

57. Smith M, Parker C, Saad F, Miller K, Tombal B, et al. Addition of radium-223 to abiraterone acetate and prednisone or prednisolone in patients with CRPC and bone metastases (ERA 223): a randomized, double-blind, placebocontrolled, phase 3 trial. Lancet Oncol. 2019; 20: 408-19. DOI: https://doi.org/10.1016/S1470-2045(18)30860-X

58. Matsubara N, Kimura G, Uemura H, Uemura H, Nakamura $\mathbf{M}$, et al. A randomized, double-blind, comparison of radium-223 and placebo, in combination with abiraterone acetate and prednisolone, in castration-resistant metastatic prostate cancer: subgroup analysis of Japanese patients in the ERA 223 study. Int J Clin Oncol. 2020; 25: 720-31. DOI: https://doi.org/10.1007/s10147-019-01589-6

59. Awang ZH, Essler M, Ahmadzadehfar H. Radioligand therapy of metastatic CRPC: current approaches. Radiat Oncol. 2018; 13: 98. DOI: https://doi.org/10.1186/s13014018-1037-7
60. Haberkorn U, Eder M, Kopka K, Babich JW, Eisenhut M. New Strategies in Prostate Cancer: Prostate-Specific Membrane Antigen (PSMA) Ligands for Diagnosis and Therapy. Clin Cancer Res. 2016; 22: 9-15. DOI: https://doi. org/10.1158/1078-0432.CCR-15-0820

61. Rahbar K, Ahmadzadehfar H, Kratochwil C, Haberkorn U, Schäfers M, et al. German Multicenter Study Investigating 177Lu-PSMA-617 Radioligand Therapy in Advanced Prostate Cancer Patients. J Nucl Med. 2017; 58: 85-90. DOI: https://doi.org/10.2967/jnumed.116.183194

62. Bögemann M, Herrmann K, Radtke JP, Rahbar K. PSMA radioligand therapy in patients with advanced prostate cancer. Urologe A. 2020; 59: 680-6. DOI: https://doi. org/10.1007/s00120-020-01205-w

63. Violet J, Jackson P, Ferdinandus J, Sandhu S, Akhurst T, et al. Dosimetry of 177Lu-PSMA-617 in Metastatic CRPC: Correlations Between Pretherapeutic Imaging and WholeBody Tumor Dosimetry with Treatment Outcomes. J Nucl Med. 2019; 60: 517-23. DOI: https://doi.org/10.2967/ jnumed.118.219352

64. Kim YJ, Kim YI. Therapeutic Responses and Survival Effects of 177Lu-PSMA-617 Radioligand Therapy in Metastatic Castrate-Resistant Prostate Cancer: A Meta-analysis. Clin Nucl Med. 2018; 43: 728-34. DOI: https://doi.org/10.1097/ RLU.0000000000002210

65. Violet J, Sandhu S, Iravani A, Ferdinandus J, Thang SP, et al. Long-Term Follow-up and Outcomes of Retreatment in an Expanded 50-Patient Single-Center Phase II Prospective Trial of 177Lu-PSMA-617 Theranostics in Metastatic CRPC. J Nucl Med. 2020; 61: 857-65. DOI: https://doi.org/10.2967/ jnumed.119.236414

TO CITE THIS ARTICLE:

Mao Y, Hu M, Yang G, Gao E, Chen W. Current Status of Castration-Resistant Prostate Cancer Drug Therapy. International Journal of Surgery: Oncology. 2021; 6(1), 41-49. DOI: https://doi.org/10.29337/ijsonco.126

Submitted: 16 June 2021 Accepted: 27 July 2021 Published: 09 August 2021

COPYRIGHT:

(c) 2021 The Author(s). This is an open-access article distributed under the terms of the Creative Commons Attribution 4.0 International License (CC-BY 4.0), which permits unrestricted use, distribution, and reproduction in any medium, provided the original author and source are credited. See http://creativecommons.org/licenses/by/4.0/.

International Journal of Surgery: Oncology is a peer-reviewed open access journal published by IJS Publishing Group. 